\title{
Women with chronic follicular gastritis positive for Helicobacter pylori express lower levels of GKN1
}

\author{
Judit Alarcón-Millán ${ }^{1}$. Sandra Ines Lorenzo-Nazario ${ }^{1}$ Hilda Jiménez-Wences ${ }^{1}$. Gabriela Elizabeth Campos-Viguri ${ }^{1}$. \\ Julio Ortiz-Ortiz ${ }^{2}$. Miguel Ángel Mendoza-Catalán ${ }^{2}$. Enoc Mariano Cortés-Malagón ${ }^{3}$ · Salomón Reyes-Navarrete ${ }^{4}$. \\ Marco Antonio Jiménez-López ${ }^{4}$. Carlos Alberto Castañón-Sánchez ${ }^{5} \cdot$ Berenice Illades-Aguiar $^{2}$. \\ Gloria Fernández-Tilapa ${ }^{1}$. Dinorah Nashely Martínez-Carrillo ${ }^{1}$ (1)
}

Received: 7 December 2019 / Accepted: 9 February 2020 / Published online: 21 February 2020

(c) The International Gastric Cancer Association and The Japanese Gastric Cancer Association 2020

\begin{abstract}
In women, serum levels of CTSB, GKN2, LIPF, LIPFG, AZGP1, TOP2A and PGA4 are proposed as predictive markers of gastric cancer. It is unknown whether GKN1 expression varies with the sex of patients with chronic gastritis or gastric cancer. We studied 36 patients with histopathological diagnosis of chronic gastritis from the state of Guerrero, Mexico. PCR was performed for $H$. pylori detection and GKN1 expression was determined by RT-qPCR and western blot. GKN1 mRNA expression was significantly lower in patients with chronic follicular gastritis than in those with chronic chemical gastritis $(p=0.00071)$. The mRNA and protein level of expression of GKN1 were significantly lower in women with chronic follicular gastritis than in men with the same condition ( $p=0.0279$ and $p=0.0014$, respectively); the lowest levels of GKN1 were detected in women with $\mathrm{H}$. pylori-positive follicular gastritis ( $p=0.0175$ and $p=0.0111$, respectively). Through a bioinformatic analysis, estrogen response elements were identified in the GKN1 promoter.
\end{abstract}

Keywords Gastrokine $1 \cdot$ Sex $\cdot$ Chronic gastritis $\cdot$ Helicobacter pylori

Dinorah Nashely Martínez-Carrillo

dinomtzcar@outlook.com

1 Laboratorio de Investigación Clínica, Facultad de Ciencias Químico Biológicas, Universidad Autónoma de Guerrero, Av. Lázaro Cárdenas s/n, Col. Haciendita, 39070 Chilpancingo, Guerrero, México

2 Laboratorio de Biomedicina Molecular, Facultad de Ciencias Químico Biológicas, Universidad Autónoma de Guerrero, Av. Lázaro Cárdenas s/n, Col. Haciendita, 39070 Chilpancingo, Guerrero, México

3 Unidad de Investigación, Laboratorio de Investigación en Genética y Cáncer, Hospital Juárez de México, Av. Instituto Politécnico Nacional 5160, Magdalena de las Salinas, Gustavo A. Madero, Ciudad de México, CDMX 07760, México

4 Instituto Estatal de Cancerología 'Dr. Arturo Beltrán Ortega', Av. Ruiz Cortines 128-A, Col. Alta Progreso, 39570 Acapulco de Juárez, Guerrero, México

5 Laboratorio de Investigación Biomédica, Hospital Regional de Alta Especialidad de Oaxaca, Aldama s/n, Col. Centro, 71256 San Bartolo Coyotepec, Oaxaca, México

\section{Introduction}

Interactions between etiological factors of gastric cancer (GC) induce alterations in the expression of proto-oncogenes and tumor suppressor genes [1]. In GC and in Helicobacter pylori infection, the expression of genes that regulate gastric homeostasis, such as Gastrokine 1 (GKN1) is altered [2]. GKN1 is a tumor suppressor that inhibits inflammation [2]. The transcript and protein of GKN1 decrease in the mucosa of patients with intestinal and diffuse-type GC [3-5] as well as in GC cell lines [6]. It is proposed that GKN1 may be a highly specific diagnostic biomarker for early GC detection [7].

Research on the transcriptome of various organisms indicates that the gene expression profile differs between sexes [8]. Sex is a factor that determines the incidence and mortality of individuals in different types of cancer [9]. In women with GC, serum levels of cathepsin B (CTSB), gastrokine 2 (GKN2), gastric lipase (LIPF), endothelial lipase (LIPFG), zinc alpha glycoprotein 2 (AZGP1), DNA topoisomerase 2-alpha (TOP2A) and pepsin A (PGA4) integrate a profile of promising predictive markers [10]. Currently, it is unknown 
if GKN1 expression varies with the sex of patients with chronic gastritis or GC. In this study, we evaluated GKN1 expression in biopsies of patients with chronic gastritis and with $H$. pylori infection and analyzed the relationship between the level of GKN1 and the sex of the patients.

\section{Material and methods}

\section{Patients}

Thirty-six biopsies of patients with histopathological diagnosis of chronic gastritis were studied. The patients underwent endoscopy at the Instituto Estatal de Cancerología "Dr. Arturo Beltrán Ortega", Acapulco, Guerrero, Mexico. The patients or their relatives signed a letter of consent. This project was approved by the bioethics committee of the Universidad Autónoma de Guerrero and by the research department of the Instituto Estatal de Cancerología "Dr. Arturo Beltrán Ortega".

\section{Detection of $\boldsymbol{H}$. pylori}

Helicobacter pylori DNA was detected using the oligonucleotides HP16SF and HPGR16SR, which amplify a 522 bp fragment of the $16 \mathrm{~S} r R N A$ gene, following the methodology described by Román-Román et al. [11].

\section{GKN1 expression}

RNA and total proteins were obtained from the biopsies with the TRIzol reagent (Invitrogen, Carlsbad, CA, USA), following the manufacturer's instructions. GKN1 mRNA expression (assay no. Hs00219734) was determined using the TaqMan RNA-to-CT 1 step kit (Thermo Fisher Scientific, Waltham, MA, USA). The relative expression of GKN1 was calculated by the $2^{-\triangle \mathrm{ct}}$ method. GAPDH (assay no. Hs99999905_m1) was used as endogenous control. GKN1 protein was detected by western blot with an anti-GKN1 monoclonal antibody at a 1:15,000 dilution (Abnova, Walnut, CA, USA). GAPDH was used as a loading control, and was detected with a specific monoclonal antibody (Santa Cruz, Dallas, TX, USA) at a 1:5000 dilution. Immunocomplexes were revealed by chemiluminescence using Immobilon (Millipore, Burlington, MA, USA) in the ChemiDoc Digital Imaging System (Bio-Rad, Hercules, CA, USA). GKN1 expression was calculated by densitometric analysis of the bands using the Image J program.

\section{Bioinformatic and statistical analyses}

Statistical analysis of the data was performed using the GraphPad Prism v5.0 (GraphPad Software, San Diego, CA,
USA) and STATA v14.0 (StataCorp, College Station, TX, USA) software. Absolute and relative frequencies of the qualitative variables were obtained, and the differences were calculated by the $X^{2}$ test. Means \pm standard deviations (SD) or medians were calculated for quantitative variables. The Student's $t$ test or the Mann-Whitney U test were used to compare the differences between the groups, respectively. A $p$ value of $<0.05$ was considered statistically significant. The bioinformatic analysis tosearch the potential binding sites of the estrogen and androgen receptors within the GKNI promoter was done using the ExPASy program [12]. The binding sites ofthe estrogen and androgen receptors to the GKNI promoter were selected considering a $p$ value of $<0.001$.

\section{Results}

Thirty-six patients with chronic gastritis were studied. The average age was 55 years (range 16-84). 47.2\% (17/36) of patients were $H$. pylori-positive (Table 1). Based on the Sydney System, 75\% (24/32) of the patients had moderate chronic gastritis and of these $84.6 \%$ were women and $68.4 \%$ were men.

Chronic chemical gastritis was present in $44.4 \%(16 / 36)$ of the patients whereas $55.6 \%$ (20/36) had chronic follicular gastritis. GKN1 mRNA expression was significantly lower in patients with chronic follicular gastritis than in those with chronic chemical gastritis ( $p=0.00071$, Fig. 1a). Likewise, GKN1 protein expression was lower in patients with chronic follicular gastritis (Fig. 2a, b), however this difference was not significant.

The levels of mRNA and protein of GKN1 were different between the types of gastritis and regarding the sex of the patients. GKN1 expression was significantly lower in women with chronic follicular gastritis compared tomales with the same condition ( $p=0.0279$, Fig. $1 \mathrm{~b} ; p=0.0014$, Fig. 2c, d). Irrespective of the sex, lower levels of GKN1

Table 1 Clinical features of chronic gastritis patients stratified by sex

\begin{tabular}{llll}
\hline Feature & \multicolumn{2}{l}{ Sex } & $p$ value \\
\cline { 2 - 3 } & $\begin{array}{l}\text { Female } \\
n=15\end{array}$ & $\begin{array}{l}\text { Male } \\
n=21\end{array}$ & \\
\hline $\begin{array}{l}\text { Age (mean } \pm \text { SD; } \\
\text { years) }\end{array}$ & $54 \pm 17.6$ & $55 \pm 12.9$ & $0.852^{\Omega}$ \\
$\begin{array}{l}\text { Helicobacter pylori } \\
\text { Ne }(\%)\end{array}$ & & \\
Negative & $8(53.3)$ & $11(52.4)$ & $0.955^{\boldsymbol{\delta}}$ \\
Positive & $7(46.7)$ & $10(47.6)$ & \\
Chronic gastritis type & $n(\%)$ & & \\
Chemical & $7(46.7)$ & $9(42.9)$ & $0.821^{\delta}$ \\
Follicular & $8(53.3)$ & $12(57.1)$ & \\
\hline
\end{tabular}

\footnotetext{
${ }^{\Omega}$ Student's $t$ test; ${ }^{\delta} X^{2}$ test.
} 
a

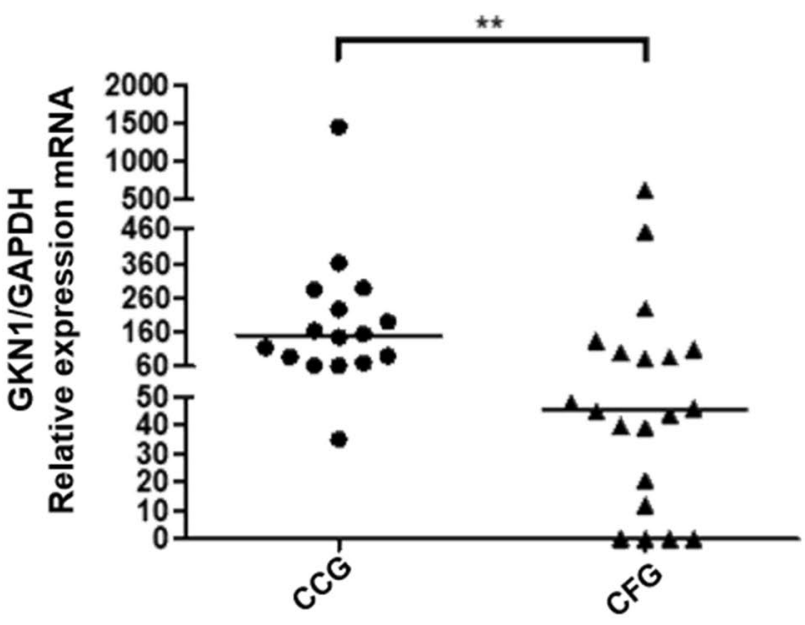

C

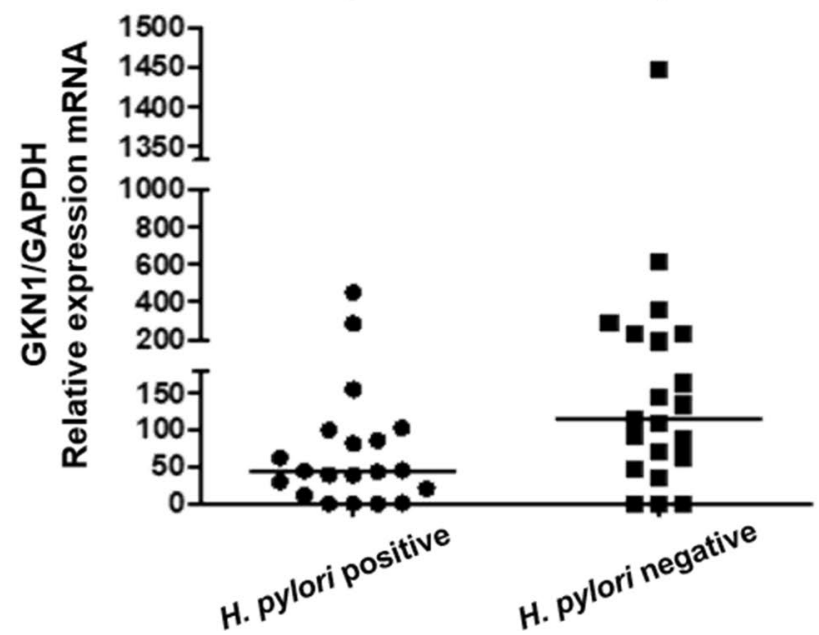

Fig. 1 GKN1 mRNA expression a by the type of gastritis; $\mathbf{b}$ in chronic chemical gastritis (CCG) and chronic follicular gastritis (CFG) grouped by sex; $\mathbf{c}$ with and without $H$. pylori in all cases; d

were detected in $H$. pylori-positive patients $(p=0.0275$, Fig. 1c; $p=0.0112$, Fig. 2e, f). Women with $H$. pyloripositive follicular gastritis expressed the lowest levels ( $p=0.0175$, Fig. $1 \mathrm{~d} ; p=0.0111$, Fig. $2 \mathrm{~g}, \mathrm{~h})$.

By means of a bioinformatic analysis, it was found that the GKN1 promoter contains four estrogen response elements (ESR1, ESR2, ESRR $\alpha$ and ESRR $\beta$ ) and an androgen response element (AR), (Fig. 3). b

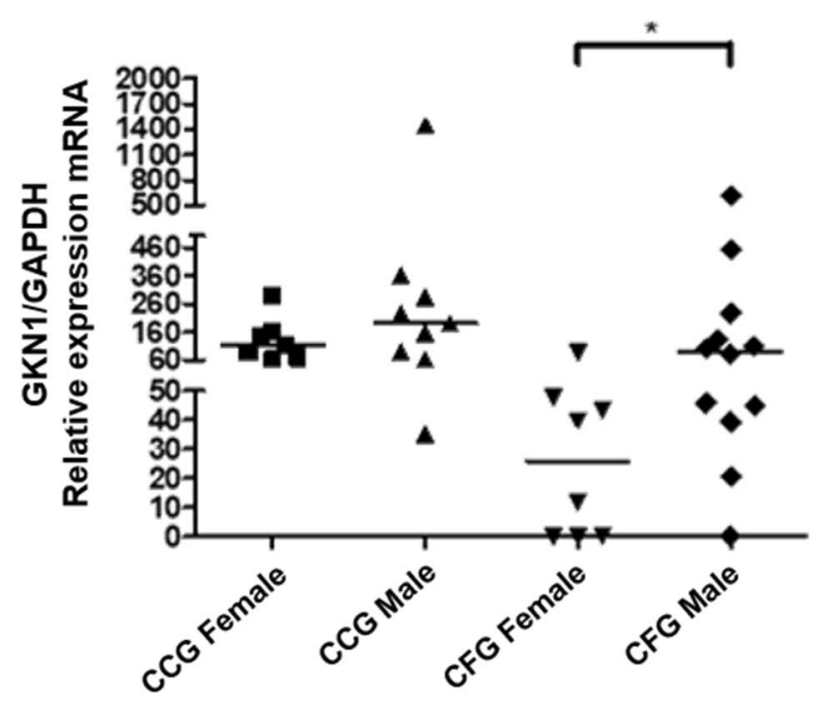

d

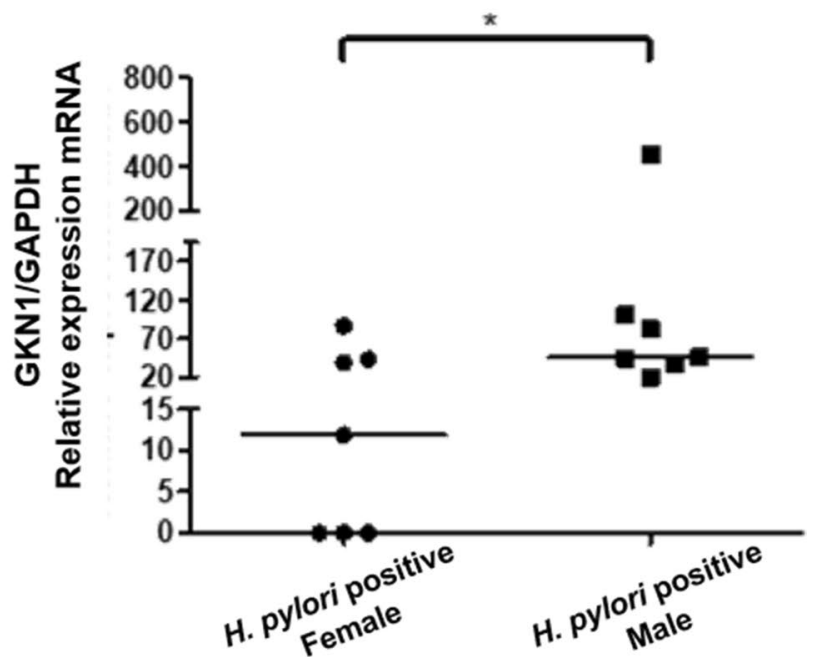

in $H$. pylori-positive chronic follicular gastritis grouped by sex. The horizontal line represents the median of $G K N 1$ expression $\left(^{*} p<0.05\right.$, $* * p<0.001)$

\section{Discussion}

GKN1 decreases in mucosa infected with $H$. pylori and is absent in uninfected gastric cancer [5, 13-15]. In this study, the expression of GKN1 was evaluated in men and women with chronic gastritis with and without $H$. pylori infection. In patients with chronic follicular gastritis, the 

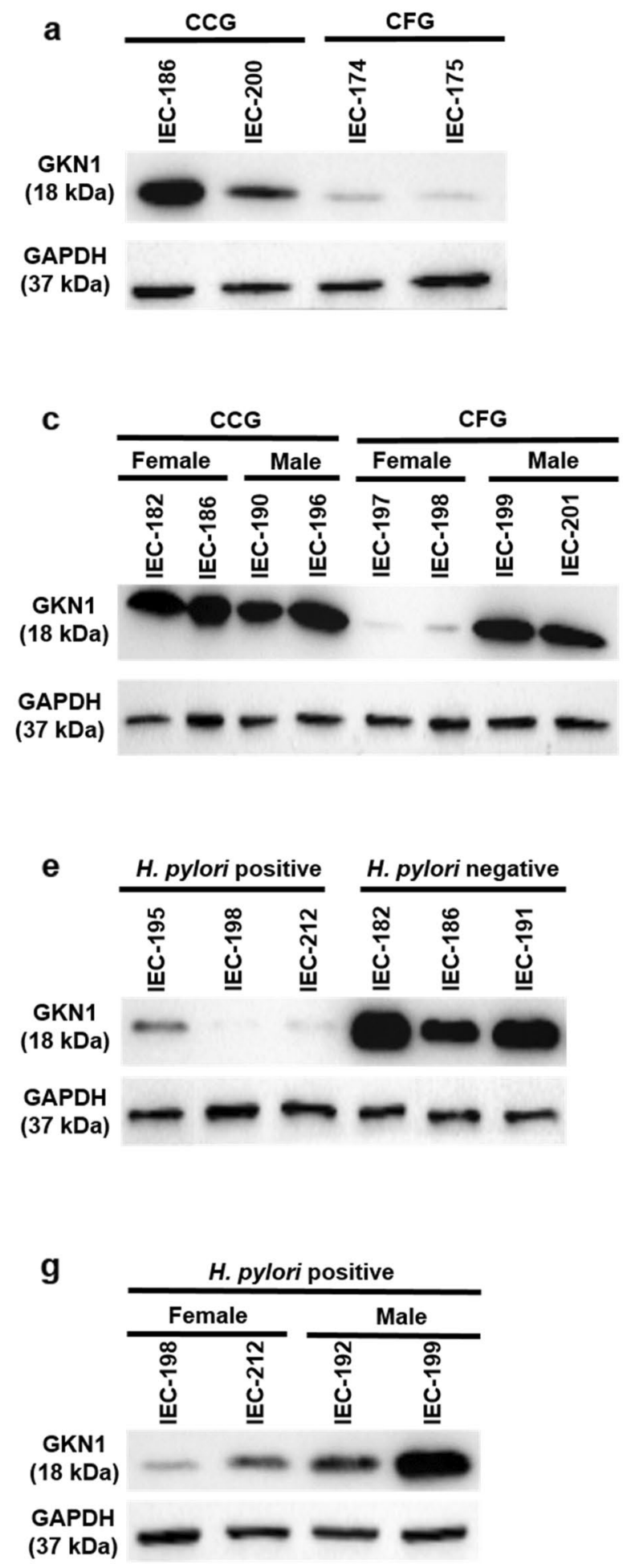

Fig. 2 Western blot of GKN1 $\mathbf{a}, \mathbf{b}$ by the type of gastritis; $\mathbf{c}, \mathbf{d}$ in chronic chemical gastritis (CCG) and chronic follicular gastritis (CFG) grouped by sex; e, $\mathbf{f}$ with and without $H$. pylori in all cases; $\mathbf{g}$, b

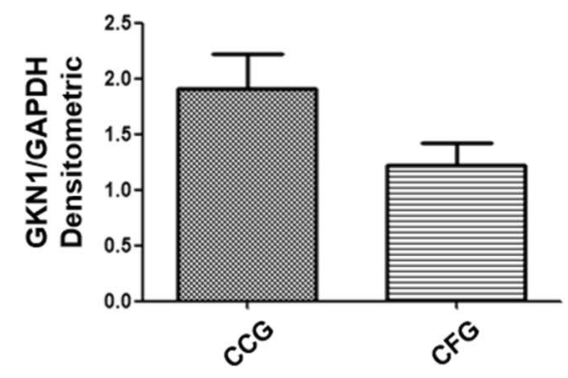

d
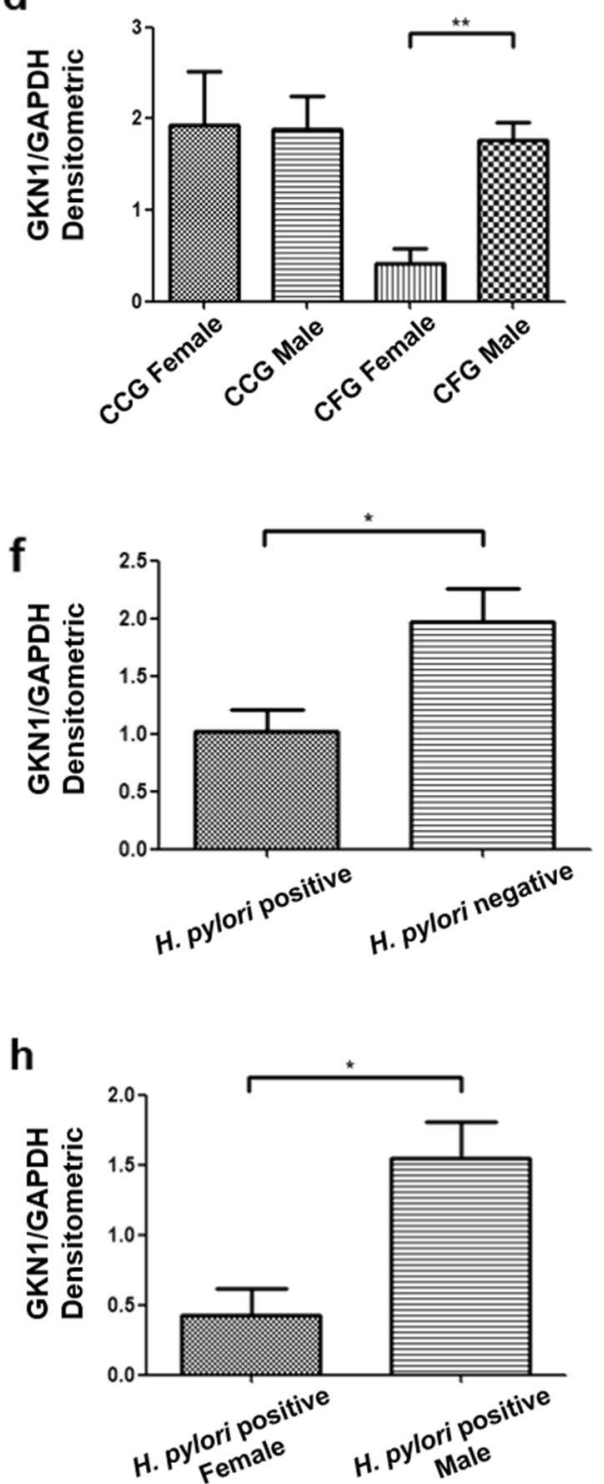

h in $H$. pylori-positive follicular gastritis cases grouped by sex. The GKN1 level was normalized with GAPDH 


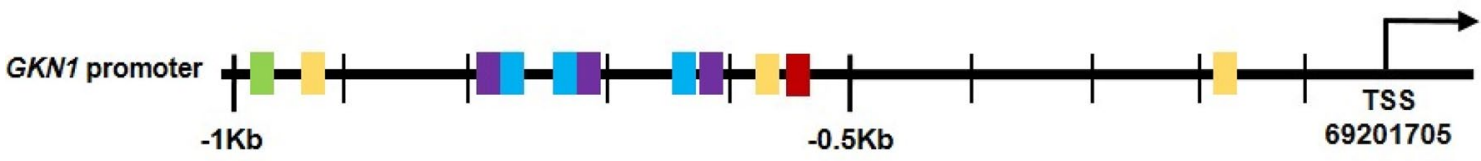

$\begin{array}{ll}\text { ERES/ARES } & \text { Position } \\ \text { ESR1 } & -974 \\ \text { ESR2 } & -934,-557,-181 \\ \text { ESRR } \alpha & -796,-712,-613 \\ \text { ESRR } \beta & -797,-711,-611 \\ \text { AR } & -543\end{array}$

Fig. 3 Estrogen and androgen response elements in the GKN1 promoter. The colored boxes show the estrogen or androgen binding sites in the GKN1 promoter from -1 to -1000 bp. TSS transcription start site, EREs estrogen response elements, AREs Androgen

expression of GKN1 mRNA was significantly lower than in patients with chronic chemical gastritis $(p<0.05)$. Patients with $H$. pylori-positive chronic gastritis express significantly lower levels of the GKNI transcript than the $H$. pylori-negative cases $(p<0.05)$. These data are consistent with those reported by Nardone et al., and Mao et al. [3, 6], who observed that in $H$. pylori-positive gastric mucosa the expression of GKN1 is decreased. The low expression of GKN1 may be due to $H$. pylori promoting the expression of AUF1, a protein that induces degradation of the GKN1 mRNA [16]. On the other hand, there may be a negative regulation of the $G K N 1$ transcript translation by non-coding RNAs [17] or degradation of the protein by ubiquitination [18]. These and other mechanisms can act synergistically and cause decrease or silencing of GKN1 expression in the gastric tissue [19].

The mRNA and protein levels of GKN1 were lower in women with chronic follicular gastritis than in men with the same condition ( $p=0.0279$ and $p=0.0014$, respectively). Women with $H$. pylori-positive chronic follicular gastritis expressed significantly lower levels of transcript and protein than infected men $(p=0.0175$ and $p=0.0111$, respectively; Figs. 1d, 2d, h). These findings suggest that, in women, in addition to $H$. pylori status and the type of gastritis, other factors modify the expression of GKN1. Taking the above point into account, it is likely that female hormones are involved in the regulation of GKN1 expression. This hypothesis is strengthened by the results of the bioinformatic analysis that in the GKN1 promoter, four estrogen response elements and an androgen response element are located (Fig. 3). The influence of sex hormones on the expression of GKN1 has not been described, however, it has been proposed that estrogens may have a protective effect on gastric cancer [20-22]. In breast cancer,
Response Elements, ESR1 estrogen receptor 1, ESR2 estrogen receptor 2, ESRR $\alpha$ estrogen-related receptor alpha, $E S R R \beta$ estrogen-related receptor beta, $A R$ androgen receptor

estrogen was reported to positively regulate the expression of Trefoil 1 protein (TFF1) [23], a protein that contributes to the protection of gastric mucosa [24]. GKN1 expression in women could be influenced by hormonal status. Considering that the age of the women studied varied from 16 to 84 years and that menopause can start at 45 , the fluctuation in estrogen production may explain, at least partially, the variation in GKN1 levels. In menopausal women ( $>45$ years) the minimum estrogen production could be related to the lower levels of GKN1 found. To strengthen these results, it is necessary to increase the sample size and conduct further studies on the differences in the expression of GKN1 in relation to the sex and age of the patients. It is imperative to elucidate the role of estrogens in GKN1 expression regulation.

Acknowledgements We express our sincere gratitude to all patients for their participation in the study, as well as to the nurses and staff of the Instituto Estatal de Cancerología who supported obtention of the biopsies. We thank. Josefina Atrisco Morales, MSc. and Ilce Valeria Román Fernández, $\mathrm{PhD}$. for the support they provided in conducting this investigation.

Author contributions All authors contributed to the study conception and design. Manuscript writing: JAM, DNMC and GFT. Data collection: JAM, SILN, GECV and EMCM. Data analyses: DNMC, JAM, JOO, MAMC, BIA and HJW. Patient management: SRN, MAJL, and CACS. Final manuscript approval: all authors.

Funding The research was carried out with the funding granted by CONACYT to Project no. 258433, in the call for Basic Scientific Research 2015-01 and with the resources granted by the Program for Strengthening Educational Quality (PFCE-SEP-2017 and 2018), of the Ministry of Public Education, to the consolidated academic body Infectious Agents and Cancer (UAGro-CA-194). Judit Alarcón-Millán is a $\mathrm{PhD}$ student in biomedical sciences and she is receiving a doctoral fellowship from CONACYT, Mexico (Grant no. 296364). Sandra Ines Lorenzo-Nazario was a fellow of CONACYT while doing her masters in biomedical sciences (Grant no. 777741). 


\section{Compliance with ethical standards}

Conflict of interest The authors have no conflict of interest.

Ethical approval This study was approved by the Bioethics Committee of the Universidad Autónoma de Guerrero and by the Research Department of the Instituto Estatal de Cancerología.

Informed consent Informed consent was obtained from all the participants.

\section{References}

1. Zhang Z, Li Z, Li Y, Zang A. MicroRNA and signaling pathways in gastric cancer. Cancer Gene Ther. 2014;21:305-16.

2. Yoon JH, Choi WS, Kim O, Park WS. The role of gastrokine 1 in gastric cancer. J Gastric Cancer. 2014;14:147-55.

3. Nardone G, Rippa E, Martin G, Rocco A, Siciliano RA, Fiengo A, et al. Gastrokine 1 expression in patients with and without Helicobacter pylori infection. Dig Liver Dis. 2007;39:122-9.

4. Moss SF, Lee JW, Sabo E, Rubin AK, Rommel J, Westley BR, et al. Decreased expression of gastrokine 1 and the trefoil factor interacting protein TFIZ1/GKN2 in gastric cancer: influence of tumor histology and relationship to prognosis. Clin Cancer Res. 2008;14:4161-7.

5. Guo XY, Dong L, Qin B, Jiang J, Shi AM. Decreased expression of gastrokine 1 in gastric mucosa of gastric cancer patients. World J Gastroenterol. 2014;20:16702-6.

6. Mao W, Chen J, Peng TL, Ying XF, Chen LZ, Chen MH. Downregulation of gastrokine- 1 in gastric cancer tissues and restoration of its expression induced gastric cancer cells to apoptosis. J Exp Clin Cancer Res. 2012;1:49-58.

7. Yoon JH, Park YG, Nam SW, Park WS. The diagnostic value of serum gastrokine 1 (GKN1) protein in gastric cancer. Cancer Med. 2019;8:5507-14.

8. Mohammadi R, Mohammadi Z, Abedi R, Cireh F, Balali A, Mohamadynejad $\mathrm{P}$, et al. Sexual dimorphism in the expression of GKN2 and FOXA2 genes in the human stomach. Mol Biol Rep. 2019;46:2355-62.

9. Kim HI, Lim H, Moon A. Sex differences in cancer: epidemiology, genetics and therapy. Biomol Ther. 2018;26:335-42.

10. Cui J, Chen Y, Chou WC, Sun L, Chen L, Suo J, et al. An integrated transcriptomic and computational analysis for biomarker identification in gastric cancer. Nucleic Acids Res. 2011;39:1197-11207.

11. Román-Román A, Martínez-Carrillo DN, Atrisco-Morales J, Azúcar-Heziquio JC, Cuevas-Caballero AS, Castañón-Sánchez
CA, et al. Helicobacter pylori vacA s1m1 genotype but not cagA or babA2 increase the risk of ulcer and gastric cancer in patients from Southern Mexico. Gut Pathog. 2017;9:18.

12. Dreos R, Ambrosini G, Périer RC, Bucher P. The eukaryotic promoter database: expansion of EPDnew and new promoter analysis tools. Nucleic Acids Res. 2015;43:D92-96.

13. Nardone G, Martin G, Rocco A, Rippa E, La Monica G, Caruso $\mathrm{F}$, et al. Molecular expression of Gastrokine 1 in normal mucosa and in Helicobacter pylori-related preneoplastic and neoplastic gastric lesions. Cancer Biol Ther. 2008;7:1890-5.

14. Yoon JH, Song JH, Zhang C, Jin M, Kang YH, Nam SW, et al. Inactivation of the gastrokine 1 gene in gastric adenomas and carcinomas. J Pathol. 2011;223:618-25.

15. Xiao JW, Chen JH, Ren MY, Tian XB, Wang CS. Relationship between expression of gastrokine 1 and clinicopathological characteristics in gastric cancer patients. Asian Pac J Cancer Prev. 2012;13:5897-901.

16. Guo Y, Zhang T, Shi Y, Zhang J, Li M, Lu F, et al. Helicobacter pylori inhibits GKN1 expression via the CagA/p-ERK/AUF1 pathway. Helicobacter. 2019;25:e12665.

17. di Stadio CS, Faraonio R, Federico A, Altieri F, Rippa E, Arcari $\mathrm{P}$. GKN1 expression in gastric cancer cells is negatively regulated by miR-544a. Biochimie. 2019;8:42-8.

18. Yang M, Jiang N, Cao QW, Ma MQ, Sun Q. The E3 ligase UBR5 regulates gastric cancer cell growth by destabilizing the tumor suppressor GKN1. Biochem Biophys Res Commun. 2016;478:1624-9.

19. Alarcon-Millán J, Martínez-Carrillo DN, Peralta-Zaragoza O, Fernández-Tilapa G. Regulation of GKN1 expression in gastric carcinogensis: a problem to resolve (Review). Int J Oncol. 2019;55:555-69.

20. Chandanos E, Lagergren J. Oestrogen and the enigmatic male predominance of gastric cancer. Eur J Cancer. 2008;44:2397-23403.

21. Nie X, Xie R, Tuo B. Effects of estrogen on the gastrointestinal tract. Dig Dis Sci. 2018;63:583-96.

22. Kim SM, Min BH, Lee J, An JY, Lee JH, Sohn TS, et al. Protective effects of female reproductive factors on Lauren intestinal type gastric adenocarcinoma. Yonsei Med J. 2018;59:28-34.

23. Masiakowski P, Breathnach R, Bloch J, Gannon F, Krust A, Chambon P. Cloning of cDNA sequences of hormone-regulated genes from the MCF-7 human breast cancer cell lines. Nucleic Acids Res. 1982;10:7895-903.

24. Aihara E, Engevik KA, Montrose MH. Trefoil factor peptides and gastrointestinal function. Annu Rev Physiol. 2017;79:357-80.

Publisher's Note Springer Nature remains neutral with regard to jurisdictional claims in published maps and institutional affiliations. 